\title{
Simvastatin use associated with low intraocular ADP levels in patients with sight-threatening diabetic retinopathy
}

\section{Tuuminen, Raimo}

2016-08

Tuuminen , R, Yegutkin , G G , Jalkanen , S \& Loukovaara , S 2016 , ' Simvastatin use associated with low intraocular ADP levels in patients with sight-threatening diabetic retinopathy ' , Graefe's Archive for Clinical and Experimental Ophthalmology , vol. 254 , no. 8 , pp. 1643-1644 . https://doi.org/10.1007/s00417-016-3349-3

http://hdl.handle.net/10138/224124

https://doi.org/10.1007/s00417-016-3349-3

publishedVersion

Downloaded from Helda, University of Helsinki institutional repository.

This is an electronic reprint of the original article.

This reprint may differ from the original in pagination and typographic detail.

Please cite the original version. 


\title{
Simvastatin use associated with low intraocular ADP levels in patients with sight-threatening diabetic retinopathy
}

\author{
Raimo Tuuminen $^{1} \cdot$ Gennady G. Yegutkin $^{2} \cdot$ Sirpa Jalkanen $^{2} \cdot$ Sirpa Loukovaara $^{3}$
}

Received: 1 February 2016/Revised: 3 April 2016/Accepted: 7 April 2016/Published online: 15 April 2016

(C) Springer-Verlag Berlin Heidelberg 2016

\section{Dear Editor,}

Purinergic signalling controls vascular thrombosis, remodelling and inflammation [1], and may result in disrupted blood flow and vascular function in the diabetic retina [2]. High glucose conditions increase secretion and reduce degradation of extracellular ATP in retinal cell culture [3], with increased purine concentrations being reported in the vitreous of diabetic patients suffering from proliferative retinopathy [4]. Administration of simvastatin, a lipophilic HMG-CoA reductase inhibitor, did not only promote direct vasculoprotective effects in experimental in vitro and ex vivo models [5], but was also associated with low levels of vasoactive and tissue remodelling factors in the retinas of diabetic rats [6] and vitreous of diabetic patients [7]. Here, we evaluated the vitreous accumulation of extracellular purine nucleotides in a total of 52 eyes of 52 type I and type II adult diabetic patients admitted to primary vitrectomy for the management of sight-threatening forms of diabetic

Raimo Tuuminen

raimo.tuuminen@helsinki.fi

1 Department of Ophthalmology, Kymenlaakso Central Hospital, Kotkantie 41, 48210 Kotka, Finland

2 MediCity Research Laboratory, University of Turku, Turku, Finland

3 Unit of Vitreoretinal Surgery, Department of Ophthalmology, Helsinki University Hospital, Helsinki, Finland retinopathy. The patients included those without statin medication $(n=41)$ and those with preoperative simvastatin treatment $(n=11)$. No difference emerged in the baseline characteristics of the patients (age, gender, HbA1c, body mass index, physical status, blood pressure, duration of diabetes) and vitrectomized eyes (intraocular pressure, lens status, intravitreal anti-VEGF treatment, macular oedema, proliferative retinopathy, vitreous haemorrhage, fibrosis) between the study groups. Vitreous samples were subjected to protein concentration measurements of adenosine 5'-triphosphate (ATP), -5'-diphosphate (ADP), -5'-monophosphate (AMP), adenosine and inosine. Intravitreal levels of proinflammatory and pro-thrombotic ADP were lower in simvastatin-treated diabetic patients (simvastatin vs. non-statin, mean \pm SEM $42.9 \pm 15.1$ vs $7.7 \pm 2.7 \mathrm{nM}$; $p=0.026$, Table 1), while the data on other purinergic factors (ATP $34.5 \pm 17.1$ vs $6.1 \pm 2.1$; AMP 1974.3 \pm 253.7 vs $1634.9 \pm 253.4$; adenosine $1066.3 \pm 235.7$ vs $1744.5 \pm 419.5$ and inosine $1163.0 \pm 456.1$ vs 2351.8 \pm 1206.2 , respectively, Table 1) led to a non-significant trend towards lower pro-inflammatory ATP and higher anti-inflammatory adenosine levels due to simvastatin treatment. These results suggest that simvastatin may favour dephosphorylation of extracellular ADP and shift the balance to an anti-inflammatory direction in the eye. Our findings are parallel with the previous report that statin use was associated with low plasma ADP levels in patients with atherosclerotic disease [8]. These data provide a novel insight into the potential vasculoprotective mechanisms of simvastatin involving extracellular purine nucleotides in patients with sight-threatening diabetic retinopathy. 
Table 1 Intravitreal purine protein concentrations in non-statin and simvastatin treated patients with diabetic retinopathy

\begin{tabular}{llll}
\hline Total protein & $\begin{array}{l}\text { Non-statin }(\mathrm{n}=41) \\
4.43 \pm 0.35\end{array}$ & $\begin{array}{l}\text { Simvastatin }(\mathrm{n}=11) \\
3.86 \pm 0.47\end{array}$ & $\begin{array}{l}p \text { value } \\
0.342\end{array}$ \\
\hline ATP metabolites & & & \\
ATP & $34.5 \pm 17.1$ & $6.1 \pm 2.1$ & 0.107 \\
ADP & $42.9 \pm 15.1$ & $7.7 \pm 2.7$ & 0.026 \\
AMP & $1974.3 \pm 253.7$ & $1634.9 \pm 253.4$ & 0.352 \\
Adenosine & $1066.3 \pm 235.7$ & $1744.5 \pm 419.5$ & 0.177 \\
Inosine & $1163.0 \pm 456.1$ & $2351.8 \pm 1206.2$ & 0.373 \\
\hline
\end{tabular}

Data are given as mean $\pm \mathrm{SEM}$. The intravitreal total $(\mathrm{mg} / \mathrm{ml})$ and purine $(\mathrm{nM})$ protein levels in eyes with diabetic retinopathy. For two-group comparisons, a two-tailed $t$ test with Welch's correction was used. ADP; adenosine 5'-diphosphate, AMP; adenosine 5'-monophosphate, ATP; adenosine 5'-triphosphate. $p \leq 0.05$ considered statistically significant

\section{Compliance with ethical standards}

Funding This study was supported by grants from the Finnish Eye Foundation, the Eye and Tissue Bank Foundation, the Mary and Georg C. Ehrnrooth Foundation, the Nissi Foundation, the Waldemar von Frenckells Foundation, and HUCH Clinical research grants (TKK4150 and TYH1325). The sponsors had no role in the design or conduct of this research.

Conflict of Interest All authors certify that they have no affiliations with or involvement in any organization or entity with any financial interest (such as honoraria; educational grants; participation in speakers' bureaus; membership, employment, consultancies, stock ownership, or other equity interest; and expert testimony or patent-licensing arrangements), or non-financial interest (such as personal or professional relationships, affiliations, knowledge or beliefs) in the subject matter or materials discussed in this manuscript.

Ethical approval All procedures performed in studies involving human participants were in accordance with the ethical standards of the institutional and/or national research committee and with the 1964 Helsinki declaration and its later amendments or comparable ethical standards.
Informed consent Informed consent was obtained from all individual participants included in the study.

\section{References}

1. Eltzschig HK, Sitkovsky MV, Robson SC (2012) Purinergic signaling during inflammation. N Engl J Med 367:2322-2333. doi:10. 1056/NEJMra1205750

2. Sugiyama T (2014) Role of P2X7 receptors in the development of diabetic retinopathy. World J Diabetes 5:141-145. doi:10.4239/wjd. v5.i2.141

3. Costa G, Pereira T, Neto AM, Cristovao AJ, Ambrosio AF, Santos PF (2009) High glucose changes extracellular adenosine triphosphate levels in rat retinal cultures. J Neurosci Res 87:1375-1380. doi:10.1002/jnr.21956

4. Loukovaara S, Sahanne S, Jalkanen S, Yegutkin GG (2015) Increased intravitreal adenosine 5'-triphosphate, adenosine 5'diphosphate and adenosine 5'-monophosphate levels in patients with proliferative diabetic retinopathy. Acta Ophthalmol 93:67-73. doi: 10.1111/aos. 12507

5. Bellosta S, Ferri N, Arnaboldi L, Bernini F, Paoletti R, Corsini A (2000) Pleiotropic effects of statins in atherosclerosis and diabetes. Diabetes Care Suppl 2:B72-B78

6. Tuuminen R, Sahanne S, Loukovaara S (2014) Low intravitreal angiopoietin-2 and VEGF levels in vitrectomized diabetic patients with simvastatin treatment. Acta Ophthalmol 92:675-681. doi:10. 1111/aos. 12363

7. Lee SG, Kim JL, Lee HK, Ryu GW, Hur DY, Yun IH, Yang JW, Kim HW (2011) Simvastatin suppresses expression of angiogenic factors in the retinas of rats with streptozotocin-induced diabetes. Graefes Arch Clin Exp Ophthalmol 249:389-397. doi:10.1007/s00417-0101496-5

8. Jalkanen J, Yegutkin GG, Hollmen M, Aalto K, Kiviniemi T, Salomaa V, Jalkanen S, Hakovirta H (2015) Aberrant circulating levels of purinergic signaling markers are associated with several key aspects of peripheral atherosclerosis and thrombosis. Circ Res 116:1206-1215. doi:10.1161/CIRCRESAHA.116. 305715 